\title{
Improving quality of life through the routine use of the patient concerns inventory for head and neck cancer patients: main results of a cluster preference randomised controlled trial
}

\author{
Simon N. Rogers ${ }^{1,2}\left(\mathbb{D} \cdot\right.$ Christine Allmark $^{3} \cdot$ Fazilet Bekiroglu $^{2} \cdot$ Rhiannon Tudor Edwards $^{4} \cdot$ Gillon Fabbroni $^{3}$. \\ Robert Flavel ${ }^{5}$. Victoria Highet ${ }^{6}$. Michael W. S. $\mathrm{Ho}^{3}$. Gerald M. Humphris ${ }^{7}$. Terry M. Jones ${ }^{8}$. Owais Khattak ${ }^{2}$. \\ Jeffrey Lancaster ${ }^{2} \cdot$ Christopher Loh $^{2} \cdot$ Derek Lowe $^{9} \cdot$ Cher Lowies $^{6} \cdot$ Dominic Macareavy $^{10} \cdot$ James Moor $^{3} \cdot$ T. K. Ong ${ }^{3}$. \\ A. Prasai ${ }^{3} \cdot$ Nicholas Roland $^{2}$. Cherith Semple ${ }^{11,12}$ - Llinos Haf Spencer ${ }^{4} \cdot$ Sank Tandon $^{2} \cdot$ Steven J. Thomas ${ }^{13}$. \\ Andrew Schache ${ }^{2} \cdot$ Richard J. Shaw ${ }^{2} \cdot$ Anastasios Kanatas $^{3}$
}

Received: 6 September 2020 / Accepted: 27 November 2020 / Published online: 21 December 2020

(c) The Author(s) 2020

\begin{abstract}
Purpose The patient concerns inventory (PCI) is a prompt list allowing head and neck cancer (HNC) patients to discuss issues that otherwise might be overlooked. This trial evaluated the effectiveness of using the PCI at routine outpatient clinics for one year after treatment on health-related QOL (HRQOL).

Methods A pragmatic cluster preference randomised control trial with 15 consultants, 8 'using' and 7 'not using' the PCI intervention. Patients treated with curative intent (all sites, disease stages, treatments) were eligible.

Results Consultants saw a median (inter-quartile range) 16 (13-26) patients, with 140 PCI and 148 control patients. Of the pre-specified outcomes, the 12-month results for the mean University of Washington Quality of Life (UW-QOLv4) socialemotional subscale score suggested a small clinical effect of intervention of 4.6 units (95\% CI 0.2, 9.0), $p=0.04$ after full adjustment for pre-stated case-mix. Results for UW-QOLv4 overall quality of life being less than good at 12 months (primary outcome) also favoured the PCI with a risk ratio of $0.83(95 \%$ CI $0.66,1.06)$ and absolute risk $4.8 \%(-2.9 \%, 12.9 \%)$ but without achieving statistical significance. Other non-a-priori analyses, including all 12 UWQOL domains and at consultant level also suggested better HRQOL with PCI. Consultation times were unaffected and the number of items selected decreased over time.

Conclusion This novel trial supports the integration of the PCI approach into routine consultations as a simple low-cost means of benefiting HNC patients. It adds to a growing body of evidence supporting the use of patient prompt lists more generally.
\end{abstract}

Keywords Head and neck cancer · Patient concerns inventory · Quality of life · Patient-reported outcomes · Intervention · Randomised trial

Abbreviations
$\begin{array}{ll}\text { DT } & \text { Distress thermometer } \\ \text { EQ-5D-5 L } & \text { EuroQol 5 dimension questionnaire } \\ \text { HNC } & \text { Head and neck cancer } \\ \text { HRQOL } & \text { Health-related quality of life } \\ \text { MDT } & \text { Multi-professional team } \\ \text { PCI } & \text { Patients concerns inventory } \\ \text { PCI-HN } & \text { Patient concerns inventory-head neck } \\ \text { QOL } & \text { Quality of life }\end{array}$

Simon N. Rogers

simonn.rogers@aintree.nhs.uk

Extended author information available on the last page of the article

\author{
RCT Randomised controlled trial \\ UWQOL University of Washington QOL \\ questionnaire \\ UWQOLv4 University of Washington QOL question- \\ naire version 4
}

\section{Introduction}

Health-related quality of life (HRQOL) is a key outcome in cancer care. The evaluation of HRQOL is complex with many factors involved [1]. For head and neck cancer (HNC) survivors, HRQOL is not only influenced by site of the tumour, stage and treatment [2] but shaped by 
patient-clinician relationship, identification of needs, participation in therapeutic alliance, and quality of the rehabilitation service provision [3]. Following treatment, HNC patients have a wide variety and level of unmet needs, with psychological unmet needs being most prevalent [4]. Emotional concerns can be difficult to elicit indicating the importance of undertaking holistic assessments in an attempt to uncover unmet needs [5].

The patient concerns inventory (PCI) was first published in 2009 [6] and is a condition-specific prompt list that allows patients to raise concerns that otherwise might be overlooked [7]. A recent systematic review and content comparison of unmet needs self-report measures used in patients with HNC favoured the PCI compared to 13 other tools [8]. The PCI consists of 56 clinical items and has been used by patients in outpatient clinics, before seeing their consultant. The list guides the outpatient consultation and it covers a range of symptoms and potential problems patients may face after treatment. It has been shown to be feasible in routine consultations $[9,10]$ and for wider adoption across a cancer network [11]. It is possible to augment the PCI with feedback from the patient as to their HRQOL outcome and one example of this is through the use of the University of Washington questionnaire (UW-QOLv4) [12, 13]. The combination of the PCI and UW-QOL has been shown to be feasible in routine practice and early evidence would suggest that their use in consultations could have a beneficial impact on quality of life [14,15]. With established cut-offs, it is possible to highlight those doing less well [16]. As outlined in the trial protocol [17] and baseline findings [18], the trial intervention involved a one-page patient summary sheet that was printed following patient completion of the questionnaires on an iPad. This information sheet showed the PCI items flagged, domains of UW-QOL dysfunction, overall QOL, distress thermometer (DT) score and number of health professionals that patients identified as possibly wishing to see, were taken into the consultation with the patient.

The PCI has never before been tested in a randomised trial. Hence, the main aim of this paper is to report the a-priori outcomes of the trial, specifically overall quality of life, social-emotional dysfunction and distress following repeated use of the PCI based summary sheet after a one-year period. Other important outcomes, such as costeffectiveness, in terms of quality-adjusted life years (QALY), health service use and costs and the cost of the PCI intervention will be reported in a separate paper.

\section{Methods}

The methods have been described in full [18]. The study was a pragmatic cluster-controlled trial conducted at two UK Cancer Centres in Aintree and Leeds, UK. All 15 eligible consultants (the clustering factor) were randomised, 8 to 'using' and 7 to 'not using' an intervention incorporating the PCI prompt list at all their trial clinics. Consultants with preferences were given their preferred group and those without preference were randomised, so as to limit the possibility of PCI-sceptics dominating the PCI group and PCI-enthusiasts the non-PCI group. Preference-based methodologies have been used in the evaluation of interventions that are about clinical behaviour change to minimise the impact of pre-conceived ideas [19]. Allocation was overseen by the trial medical statistician, before any patient recruitment and was blind to consultant name. In Leeds, three consultants preferred to use the PCI, while three without preference became controls. In Liverpool, three consultants preferred to be controls and the other five without preference were randomised, one as a control and four to using the PCI. A new Aintree consultant, in post soon after the trial began, was randomised to the PCI group. Quality assurance was by initial training and booster sessions for PCI consultants and through a post-consultation survey of PCI patients asking how much the consultant had made reference to the PCI prompt sheet during the consultation.

Eligible patients were treated curatively for primary HNC and included all sites, stages of disease and treatments. Patients treated palliatively or for recurrence, or with history of cognitive impairment, psychoses or dementia were excluded. The first baseline clinic was in April 2017, and to aid recruitment to this novel trial, second primary tumours were accepted from January 2018. Eligible patients were given written information about the trial and willing participants were asked to provide written consent when they next attended hospital. Patients consented to their clinical data being used and to completing research questionnaires before each post-treatment consultation, information from which could be used in their consultation. Neither consultants nor patients were blind to the randomisation, this being a pragmatic trial.

Pre-consultation questionnaires including the PCI prompt list were completed electronically apart from one Liverpool hospital (non-PCI consultant) that used paper. Patient concerns inventory patients took into their consultations a summary sheet of paper that listed (a) all PCI items they selected for discussion, (b) any University of Washington (UWQOL) questionnaire domains in which there was a significant problem or dysfunction, (c) their overall QOL response (d) their DT score and (e) health professionals they wanted to see. This one-page paper summary printout was the visible difference between trial arms as far as contact between consultant and patient was concerned. Control patients completed exactly the same pre-clinic information apart from the PCI prompt list but neither they nor their consultant saw any summary sheet. Both groups completed the EQ-5D-5L for purposes of health economic assessment. 
Clinical and demographic data were collected by a baseline questionnaire or by extraction from electronic records. HRQOL data included UW-QOLv4 [12], the DT [20] and EQ-5D-5L [21]. The UW-QOL v4 questionnaire consists of 12 single-item domains, with 3-5 response options scored evenly from 0 (worst) to 100 (best) according to response hierarchy. UW-QOL domains are presented within two subscales, physical function and social-emotional function [22]. The physical function score is the mean of the appearance, swallowing, chewing, speech, taste and saliva domain scores, while the social-emotional score is the mean of the pain, activity, recreation, shoulder, mood and anxiety domain scores. Criteria derived from earlier work can indicate the domains in which patients have a significant problem or dysfunction [16]. A single overall QOL question on the UWQOL v4 asks patients to consider not only physical and mental health, but also other factors, such as family, friends, spirituality or personal leisure activities important to their enjoyment of life; response options are outstanding, very good, good, fair, poor, and very poor.

Trial patients were seen in clinic after treatment as per normal routine. For analysis, 'intermediate' (91-273 days) and 'final' ( $\geq 274$ days) time windows captured the clinics that fell close to 6 months (183 days) and 12 months (365 days) after the baseline trial clinic. For patients seen more than once in the intermediate window, the closest clinic to 183 days was selected for analysis. In the final window, priority selection was given to patients seen after 12 months and failing this the closest to 365 days. In this paper, we will simply refer to results being 'at 6 months' and 'at 12 months'.

The pre-specified primary outcome measure was the percentage with less than good overall QOL (UWQOLv4) at 12 months. Two pre-specified secondary outcomes were (A) the percentage with a DT score $\geq 4$ and (B) the mean social-emotional subscale score of the UWQOLv4. Assuming a control group outcome of $30 \%$ for the primary outcome, an intra-cluster correlation (ICC) value of 0.01 , a cluster size of 30 , and not wishing to miss a halving in outcome, then 312 patients from $\geq 10$ consultants were required (with $80 \%$ power, $5 \%$ level of significance) at 12 months. After factoring in 25\% attrition/non-consent, 416 were to be identified at Multidisciplinary Team (MDT) Meetings. For DT $\geq 4$, an ICC of 0.01 and a control outcome of $34 \%$ anticipated, 294 patients were required at 12 months to avoid missing a halving in outcome. For the social-emotional subscale score, an ICC of 0.025 and a control mean of 75 anticipated, 221 patients were required at 12 months to avoid missing a 10-unit difference in means.

Inference targeted patient outcomes at 12 months. For binary outcomes (overall QOL, DT) binary regression (STATA v13 binreg procedure) with the $r r$ link option estimated treatment-effect risk ratios/differences, $P$ values and 95\% confidence intervals, with standard errors robust to intra-cluster correlation obtained using the option "cluster'. Logistic regression (STATA logit) with robust standard errors and cluster option was also used. Estimates were adjusted for baseline values of the outcome, for consultant clustering and for pre-specified covariates of gender, age $(<55,55-64,65-74, \geq 75)$, tumour site (oral cavity, oropharynx, larynx, other), overall clinical grade (early 1-2, advanced 3-4), treatment (surgery only, RT or CT/RT only, surgery with RT or CT/RT,) and free-flap transfer treatment (Yes, No, No surgery). Random effects linear regression (STATA $x$ treg procedure) estimated the treatment-effect difference in UWQOL socio-emotional mean subscale scores, with adjustments for baseline subscale scores (quintile categories), for consultant clustering and for the pre-specified covariates. Standard errors were estimated by a cluster bootstrap that resampled with replacement over consultant clusters. In non-apriori analyses, the UWQOL physical function subscale score and all 12 UWQOL domain scores were analysed in the same way using random effects linear regression. Quintile categories were created for baseline physical function subscale scores and a three-level categorisation into best score (100), dysfunction, and in-between these extremes was used for baseline UWQOL domain scores. We used the estimator provided by the loneway command in STATA $v 13$ to estimate outcome ICCs.

The PCI trial had ethical approval from North WestLiverpool Central Research Ethics Committee REC reference: IRAS 16/NW/0465, Project ID: 189,554. It also had approval from the Health Research Authority (HRA).

The study closed formally on the 30 June 2020 following lockdown due to COVID-19 in England on the 24 March 2020 .

\section{Results}

Fifteen consultants were eligible and all participated throughout the trial seeing a median [Inter-Quartile Range (IQR)] of 16 (13-26) patients, range 5-48. Baseline clinics ran from April 2017 to October 2019 with 140 intervention PCI and 148 control patients and a total of 1186 trial clinic appointments. Median IQR number of clinics for PCI patients was 4 (3-5), range 1-10, and for controls 4 (3-6), range 1-10. A detailed patient flow chart from MDT to baseline clinic has been published [18]. Figure 1 shows the flow chart from baseline clinic through to completion of the trial. There were final clinic data for $71 \%$ of patients in each trial group, median IQR 69\% (56-82\%) for the 15 consultants. Nearly half $(46 \%)$ of the patient attrition was due to cancer recurrence, palliation, 2nd primary and death, with 5 patients dying (2 PCI, 3 control). One-quarter (27\%) of the overall loss was due to early closure of the trial because 
Fig. 1 Patient flow from trial baseline to final clinic

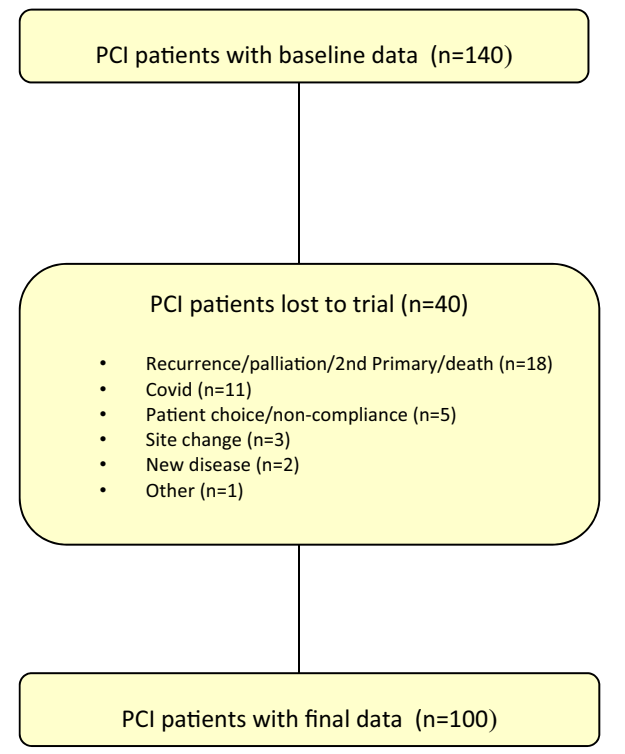

of the COVID-19 pandemic; only 14\% was due to patient choice/non-compliance. Final trial clinics (referred to as at 12 months) were a median IQR of 357 (329-380) days after baseline for 100 PCI patients and 364 (322-396) days for 105 controls; intermediate clinics (at 6 months) were 182 (147-210) days, $n=113$ and 175 (147-196) days, $n=126$, respectively.

Baseline characteristics of PCI and control groups have already been described [18]; briefly, the two trial groups were similar in demographic and clinical characteristics as well as in HRQOL measures apart from differences in tumour location, tumour staging and mode of treatment. These exceptions were cluster (consultant) related with MFU and ENT consultants seeing different types of cases. Baseline characteristics of patients with final outcome data can be seen in Table 1, and apart from tumour site and mode of treatment, the balance between PCI and control groups was broadly similar. Overall loss to follow-up was higher in patients living alone, not working, in households receiving benefits and living in more deprived neighbourhoods. It was also higher in those with worse HRQOL and in those having free-flap transfer surgery followed by adjuvant therapy.

The median IQR number of PCI items was 5 (2-9) at baseline, reducing to $3(1-7)$ at 6 months and $2(0-4)$ at 12 months. Dry mouth was the most frequent item selected, $49 \%$ at baseline, $29 \%$ at 6 months and $25 \%$ at 12 months (Fig. 2). Other items most selected throughout the trial were fear of the cancer coming back, chewing/eating, salivation, fatigue/tiredness and pain in the head/neck. The percentage of patients selecting one or more health professionals they wanted to see was $46 \%(65 / 140)$ at baseline, $31 \%(35 / 113)$ at 6 months and $18 \%(18 / 100)$ at 12 months. Professionals most selected at baseline were dentist $(16 \%, 22)$, surgeon $(14 \%, 19)$, radiotherapist/oncologist $(9 \%, 12)$, Speech
\& Language therapist $(8 \%, 11)$ and dental hygienist $(8 \%$, 11 ). In the post-consultation questionnaire, the vast majority of PCI patients said that their consultant had made 'a great deal' of reference to the PCI prompt sheet during the consultation, $88 \%(117 / 133)$ at baseline, $90 \%(97 / 108)$ at 6 months and 93\% $(91 / 98)$ at 12 months. In most other instances $(13 / 133,7 / 108,5 / 98)$, consultants had 'somewhat' referenced the prompt sheet, and rarely had they made 'a little' $(3,3,1)$ reference or 'not at all' $(0,1,1)$. Median IQR consultation times at baseline were $11(8-15)$ minutes for $138 \mathrm{PCI}$ and 10 (7-13) minutes for 148 control patients; at 6 months: 10 (7-12) minutes for $112 \mathrm{PCI}$ and 10 (7-11) minutes for 126 controls; at 12 months: 8 (7-11) minutes for 97 PCI and 9 (6-12) minutes for 103 controls.

Results for the primary outcome measure, i.e. the percentage of patients at 12 months with overall QOL that was less than good, favoured the PCI intervention though these results were not statistically significant (Table 2). In the PCI group, the percentage fell from $30 \%$ at baseline to $22 \%$ at 12 months whilst in the control group, it fell from 27 to $25 \%$. After adjustment for baseline outcome, consultant clustering, tumour site and treatment (including free-flap transfer), the estimate of risk ratio at 12 months was 0.83 (95\% CI 0.66, 1.06), $p=0.14$. Similar adjustments regarding absolute risk difference gave an estimate of $4.8 \%$ in favour of PCI over control with 95\% confidence interval ranging from $2.9 \%$ against PCI to $12.9 \%$ for PCI. Results for the percentage of patients at 12 months with a DT score $\geq 4$ did not favour either group after adjustment (Table 3); in the PCI group, the percentage fell from $45 \%$ at baseline to $33 \%$ at 12 months whilst in the control group, it fell from $36 \%$ to $30 \%$. However, it was not possible to further adjust either binary measure for age, gender or overall clinical stage because of convergence issues. Estimation of odds ratios 
Table 1 Baseline characteristics of those with final data, and loss to follow-up

\begin{tabular}{|c|c|c|c|c|c|c|}
\hline & \multicolumn{2}{|c|}{$\begin{array}{l}\text { Patients with } \\
\text { final data }\end{array}$} & \multicolumn{2}{|c|}{$\begin{array}{l}\text { Patients without } \\
\text { final data }\end{array}$} & \multirow{2}{*}{$\begin{array}{l}\text { Overall loss to } \\
\text { follow-up } \\
\%\end{array}$} & \multirow[t]{2}{*}{$p$ value ${ }^{*}$} \\
\hline & PCI & Control & PCI & Control & & \\
\hline All patients & 100 & 105 & 40 & 43 & 29 & \\
\hline \multicolumn{7}{|l|}{ Site } \\
\hline Aintree & 55 & 64 & 27 & 32 & 33 & \multirow[t]{2}{*}{0.05} \\
\hline Leeds & 45 & 41 & 13 & 11 & 22 & \\
\hline \multicolumn{7}{|l|}{ Gender } \\
\hline Female & 35 & 27 & 14 & 14 & 31 & \multirow[t]{2}{*}{0.58} \\
\hline Male & 65 & 78 & 26 & 29 & 28 & \\
\hline \multicolumn{7}{|l|}{ Age at baseline clinic } \\
\hline$<55$ & 20 & 29 & 9 & 13 & 31 & \multirow[t]{4}{*}{0.68} \\
\hline $55-64$ & 45 & 42 & 17 & 12 & 25 & \\
\hline $65-74$ & 23 & 23 & 9 & 12 & 31 & \\
\hline$\geq 75$ & 12 & 11 & 5 & 6 & 32 & \\
\hline \multicolumn{7}{|l|}{ Tumour site } \\
\hline Oral cavity & 38 & 53 & 17 & 26 & 32 & \multirow[t]{4}{*}{0.08} \\
\hline Oropharynx & 33 & 37 & 9 & 12 & 23 & \\
\hline Larynx & 17 & 8 & 13 & 3 & 39 & \\
\hline Other & 12 & 7 & 1 & 2 & 14 & \\
\hline \multicolumn{7}{|l|}{ Overall stage } \\
\hline Early $0-2$ & 40 & 49 & 16 & 19 & 28 & \multirow[t]{2}{*}{0.90} \\
\hline Advanced 3-4 & 60 & 56 & 24 & 24 & 29 & \\
\hline \multicolumn{7}{|l|}{ Primary treatment ${ }^{* *}$} \\
\hline S only & 36 & 37 & 10 & 12 & 23 & \multirow[t]{5}{*}{0.06} \\
\hline S only \& FF & 5 & 12 & 2 & 2 & 19 & \\
\hline RT or RT/CT only & 26 & 13 & 12 & 7 & 33 & \\
\hline $\mathrm{S} \&(\mathrm{RT}$ or RT/CT $)$ & 24 & 27 & 7 & 10 & 25 & \\
\hline $\mathrm{S} \&(\mathrm{RT}$ or RT/CT $) \& \mathrm{FF}$ & 9 & 16 & 9 & 12 & 46 & \\
\hline \multicolumn{7}{|l|}{ WHO comorbidity } \\
\hline 0 & 65 & 63 & 23 & 28 & 28 & \multirow[t]{3}{*}{0.28} \\
\hline 1 & 23 & 28 & 5 & 11 & 24 & \\
\hline $2-4$ & 12 & 14 & 12 & 4 & 38 & \\
\hline \multicolumn{7}{|l|}{ ACE27 comorbidity } \\
\hline None & 58 & 49 & 13 & 17 & 22 & \multirow[t]{3}{*}{0.08} \\
\hline Mild & 26 & 35 & 15 & 19 & 36 & \\
\hline Moderate/severe & 16 & 21 & 12 & 7 & 33 & \\
\hline \multicolumn{7}{|l|}{ Living situation in house/flat } \\
\hline Alone & 18 & 21 & 11 & 15 & 40 & 0.03 \\
\hline With others & 82 & 83 & 29 & 26 & 25 & \\
\hline Working & & & & & & \\
\hline Yes & 41 & 31 & 7 & 9 & 18 & 0.01 \\
\hline No & 55 & 73 & 31 & 33 & 33 & \\
\hline Financial benefits (househol & & & & & & \\
\hline Yes & 30 & 38 & 19 & 20 & 36 & 0.007 \\
\hline No & 64 & 61 & 14 & 19 & 21 & \\
\hline Smoking habit & & & & & & \\
\hline Current & 12 & 12 & 4 & 9 & 35 & 0.60 \\
\hline Former & 60 & 57 & 21 & 25 & 28 & \\
\hline Never & 26 & 33 & 12 & 9 & 26 & \\
\hline Alcohol habit & & & & & & \\
\hline
\end{tabular}


Table 1 (continued)

\begin{tabular}{|c|c|c|c|c|c|c|}
\hline & \multicolumn{2}{|c|}{$\begin{array}{l}\text { Patients with } \\
\text { final data }\end{array}$} & \multicolumn{2}{|c|}{$\begin{array}{l}\text { Patients without } \\
\text { final data }\end{array}$} & \multirow{2}{*}{$\begin{array}{l}\text { Overall loss to } \\
\text { follow-up } \\
\%\end{array}$} & \multirow[t]{2}{*}{$p$ value } \\
\hline & PCI & Control & PCI & Control & & \\
\hline Current & 80 & 66 & 20 & 28 & 25 & 0.08 \\
\hline Former & 15 & 30 & 15 & 13 & 38 & \\
\hline Never & 4 & 6 & 1 & 2 & 23 & \\
\hline \multicolumn{7}{|l|}{ IMD 2019 quintile } \\
\hline $1=$ least deprived & 12 & 14 & 4 & 4 & 24 & 0.01 \\
\hline 2 & 23 & 22 & 6 & 4 & 18 & \\
\hline 3 & 18 & 22 & 4 & 5 & 18 & \\
\hline 4 & 12 & 10 & 5 & 13 & 45 & \\
\hline $5=$ most deprived & 35 & 37 & 21 & 17 & 35 & \\
\hline \multicolumn{7}{|l|}{ UWQOL Overall Quality of life } \\
\hline Good, V good, Outstanding & 70 & 77 & 25 & 27 & 26 & 0.16 \\
\hline Fair, Poor, V poor & 30 & 28 & 15 & 16 & 35 & \\
\hline \multicolumn{7}{|l|}{ Distress thermometer (DT) score } \\
\hline $0-3$ & 55 & 67 & 19 & 18 & 23 & 0.03 \\
\hline $4-10$ & 45 & 38 & 21 & 25 & 36 & \\
\hline \multicolumn{7}{|c|}{$\begin{array}{l}\text { UWQOL social-emotional subscale } \\
\text { score (quintiles) }\end{array}$} \\
\hline$<55.8$ & 10 & 19 & 10 & 18 & 49 & 0.002 \\
\hline $55.9-70.0$ & 21 & 22 & 9 & 10 & 31 & \\
\hline $70.1-81.7$ & 25 & 20 & 7 & 3 & 18 & \\
\hline $81.8-90.8$ & 18 & 16 & 8 & 5 & 28 & \\
\hline $90.9-100$ & 26 & 28 & 6 & 7 & 19 & \\
\hline
\end{tabular}

$S$ Surgery, RT Radiotherapy, $C T$ Chemotherapy, $F F$ Free flap transfer

*Fishers exact test

gave a similar progression in regard to the primary outcome $(0.86,0.77,0.75$ with 0.78 after further adjustment for age, gender and stage) and for the DT (1.12, 1.00, 1.18 and then 0.99). Results for the other a-priori outcome, the UWQOL social-emotional subscale mean score at 12 months, also favoured the PCI intervention and these results were statistically significant (Table 4), with the best estimate suggesting a small clinical effect of 4.6 units (95\% CI 0.2, 9.0), $p=0.04$ after full adjustment.

Since the subscale score is the average of six domain scores, a set of extra analyses were done for each domain (Table 5), and all of these analyses favoured the PCI intervention, with a mix of small effects suggested for each domain. Similar analyses of the UWQOL physical function subscale mean score at 12 months, and its six component domains, also favoured the PCI intervention with small effects observed throughout. The full response range for the overall QOL (Table 6) indicated a tendency within each level of QOL at baseline for the PCI group to have a better set of QOL responses at 12 months; overall QOL improved for $42 \%$ (42) of PCI patients and 30\% (31) of control patients. Table 7 provides a more simplistic cluster-level descriptive summary of the trial data. Six of the 8 PCI consultants saw a reduction in the number of their patients having less than good overall QOL, in contrast to 3 of the 7 control consultants. The changes in mean socio-emotional subscale scores tended to be larger in patients under PCI consultants (median 7.5) than control consultants (median 3).

\section{Discussion}

Interventions aimed at improving the quality of life (QoL) of HNC survivors are of critical importance when considering the increasing number of survivors and the significant life-long treatment burden for some patients who have poor functional, emotional and social outcomes. It is essential to provide robust evidence from randomised trials about the effectiveness of psychologically-based interventions intended to improve QoL and its subscales. Thus far, such intervention studies in HNC patients have produced insufficient data to support their effectiveness for improving quality of life [23-27]. However, there is evidence of benefit in other cancers, for example, a randomised trail reporting symptom monitoring with patient-reported outcomes during routine cancer treatment [28]. In addition, van der Meulen [29] 


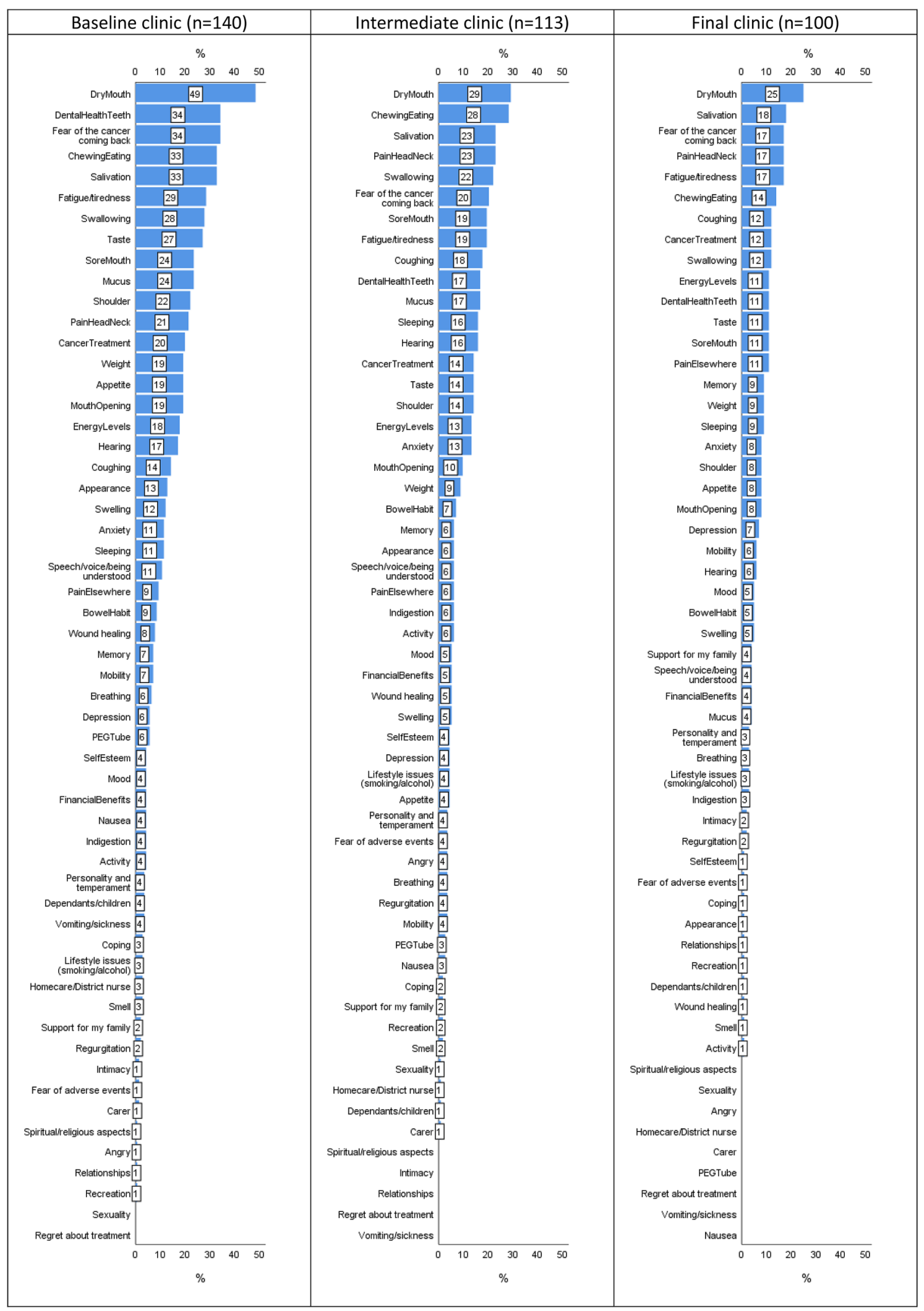

Fig. 2 PCI items selected at baseline, intermediate and final clinics 
Table 2 Pre-specified primary outcome: less than good overall QOL at 12 months

\begin{tabular}{|c|c|c|c|c|c|c|c|c|c|}
\hline & \multirow{2}{*}{\multicolumn{2}{|c|}{ Baseline }} & \multirow{2}{*}{\multicolumn{2}{|c|}{6 months }} & \multirow{2}{*}{\multicolumn{2}{|c|}{12 months }} & \multicolumn{3}{|c|}{$\begin{array}{l}\text { Risk ratio at } 12 \text { months, } \\
\text { with } 95 \% \text { confidence interval and } p \text { value }\end{array}$} \\
\hline & & & & & & & \multirow[t]{2}{*}{ Unadjusted } & \multirow{2}{*}{$\begin{array}{l}\text { Adjusted for baseline QOL } \\
\& \text { consultant clustering }{ }^{\mathrm{a}}\end{array}$} & \multirow{2}{*}{$\begin{array}{l}\text { Adjusted also for tumour } \\
\text { site, treatment \& free-flap }\end{array}$} \\
\hline & $\%$ & $n$ & $\%$ & $n$ & $\%$ & $n$ & & & \\
\hline \multicolumn{10}{|c|}{ Data at baseline and in 12 month window } \\
\hline PCI & 30 & $30 / 100$ & & & 22 & $22 / 100$ & \multirow{2}{*}{$\begin{array}{l}0.89(0.54,1.46) \\
p=0.64\end{array}$} & \multirow{2}{*}{$\begin{array}{l}0.85(0.59,1.24) \\
p=0.40\end{array}$} & \multirow{2}{*}{$\begin{array}{l}0.83(0.66,1.06) \\
p=0.14\end{array}$} \\
\hline Control & 27 & $28 / 105$ & & & 25 & $26 / 105$ & & & \\
\hline \multicolumn{10}{|c|}{ All available data } \\
\hline PCI & 32 & $45 / 140$ & 24 & $27 / 113$ & 22 & $22 / 100$ & & & \\
\hline Control & 30 & $44 / 148$ & 24 & $30 / 126$ & 25 & $26 / 105$ & & & \\
\hline \multicolumn{10}{|c|}{ Data at baseline and in both 6 and 12 month windows } \\
\hline PCI & 29 & $26 / 90$ & 21 & $19 / 90$ & 22 & $20 / 90$ & & & \\
\hline Control & 26 & $26 / 101$ & 19 & $19 / 101$ & 24 & $24 / 101$ & & & \\
\hline
\end{tabular}

${ }^{a}$ ICC Intra-class correlation estimated as Zero, with $95 \%$ confidence interval $(0,0.058)$

Table 3 Pre-specified secondary outcome: distress thermometer (DT) score $\geq 4$ at 12 months

\begin{tabular}{|c|c|c|c|c|c|c|c|c|c|}
\hline & \multicolumn{2}{|c|}{ Baseline } & \multicolumn{2}{|c|}{6 months } & \multicolumn{2}{|c|}{12 months } & \multicolumn{3}{|c|}{ Risk ratio at 12 months, with $95 \%$ confidence interval and $p$ value } \\
\hline & \multirow[b]{2}{*}{$\%$} & \multirow[b]{2}{*}{$n$} & \multirow[b]{2}{*}{$\%$} & \multirow[b]{2}{*}{$n$} & \multirow[b]{2}{*}{$\%$} & \multirow[b]{2}{*}{$n$} & \multirow[t]{2}{*}{ Unadjusted } & \multirow{2}{*}{$\begin{array}{l}\text { Adjusted for baseline DT } \\
\& \text { consultant clustering }\end{array}$} & \multirow{2}{*}{$\begin{array}{l}\text { Adjusted also for tumour } \\
\text { site, treatment \& free-flap }\end{array}$} \\
\hline & & & & & & & & & \\
\hline \multicolumn{10}{|c|}{ Data at baseline and in 12 month window: } \\
\hline PCI & 45 & $45 / 100$ & & & 33 & $33 / 100$ & $1.08(0.73,1.62)$ & $0.93(0.60,1.46)$ & $1.04(0.68,1.59)$ \\
\hline Control & 36 & $38 / 105$ & & & 30 & $32 / 105$ & $p=0.70$ & $p=0.76$ & $p=0.85$ \\
\hline \multicolumn{10}{|c|}{ All available data } \\
\hline PCI & 47 & $66 / 140$ & 41 & $46 / 113$ & 33 & $33 / 100$ & & & \\
\hline Control & 43 & $63 / 148$ & 37 & $47 / 126$ & 30 & $32 / 105$ & & & \\
\hline \multicolumn{10}{|c|}{ Data at Baseline and in both 6 and 12 month windows: } \\
\hline PCI & 46 & $41 / 90$ & 38 & $34 / 90$ & 34 & $31 / 90$ & & & \\
\hline Control & 36 & $36 / 101$ & 37 & $37 / 101$ & 29 & $29 / 101$ & & & \\
\hline
\end{tabular}

${ }^{a}$ ICC Intra-class correlation estimated as 0.00345 , with $95 \%$ confidence interval $(0,0.064)$

reported that nurse-led psychosocial intervention between 12 and 24 months after HNC treatment did make a significant improvement in emotional and physical functioning, pain, swallowing, social contact, mouth opening and depressive symptoms.

The outpatient consultation provides an ideal opportunity for integration of a prompt list intervention. The PCI can be routinely integrated into clinical care $[9,10]$, and a holistic patient-centred approach seems appropriate anyway regardless of any significant findings. Furthermore, it is something much appreciated and widely accepted by most patients [11]. Its use adds an element of quality assurance particularly when the patient is less familiar to the consultant or is being reviewed by a more junior member of staff. The consultants' training focused on ensuring that issues identified by the patient were considered and if there were too many issues raised, there was then an agreement with the patient to focus on three or four they felt most important. The post-consultation questionnaire confirmed that the patients felt the PCI had been used throughout the trial.

The purpose of this paper was to focus on a number of outcomes that were specified in advance and for which sample size calculations were made. Variables used to adjust the analyses were also specified in advance, and included tumour site, stage and treatment. Therefore, the main confidence interval estimations can be interpreted without concern about post hoc selection. Other analyses should be regarded as exploratory. Our findings should have generalisability given that all eligible consultants from the two hospitals participated throughout the trial. In addition, there was good recruitment and sustainability throughout the trial in those patients often hard to reach, such as the elderly and those in more socially deprived groups. The choice of a cluster design is a strength of the study, the rationale 


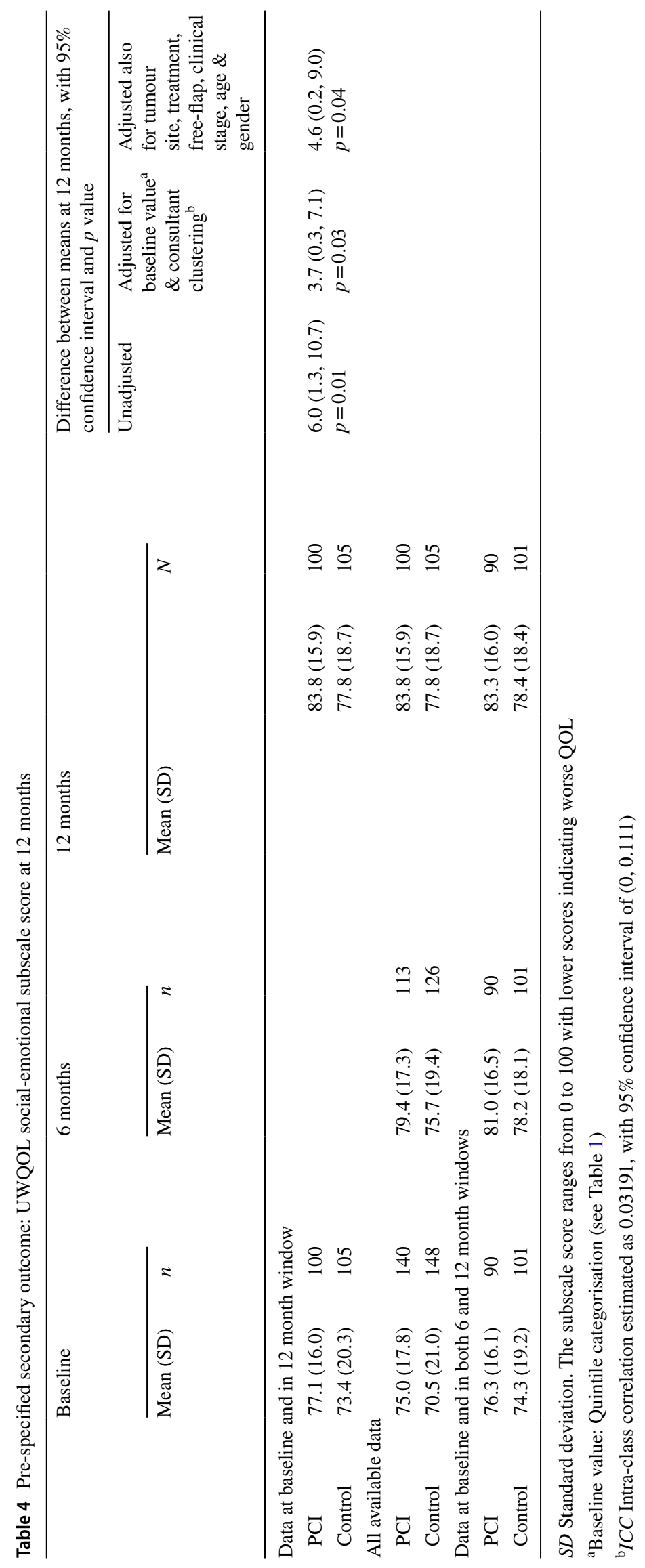


Table 5 Other UWQOL outcomes (not pre-specified) for $100 \mathrm{PCI}$ and 105 control patients with data at baseline and at 12 months

\begin{tabular}{|c|c|c|c|c|c|c|c|}
\hline & \multicolumn{4}{|c|}{ Mean (SD) } & \multicolumn{3}{|c|}{$\begin{array}{l}\text { Difference between group means at } 12 \text { months, } \\
\text { with } 95 \% \text { confidence interval and } p \text { value }\end{array}$} \\
\hline & \multicolumn{2}{|l|}{ Baseline } & \multicolumn{2}{|c|}{12 months } & \multirow[t]{2}{*}{ Unadjusted } & \multirow{2}{*}{$\begin{array}{l}\text { Adjusted for baseline } \\
\text { value }^{\mathrm{a}} \text { and consultant } \\
\text { clustering }\end{array}$} & \multirow{2}{*}{$\begin{array}{l}\text { Adjusted also for tumour site, } \\
\text { treatment, free-flap, clinical } \\
\text { stage, age and gender }\end{array}$} \\
\hline & PCI & Control & PCI & Control & & & \\
\hline \multicolumn{8}{|c|}{ UWQOL social-emotional subscale domain scores } \\
\hline Pain & $73(26)$ & $71(29)$ & $88(20)$ & $80(27)$ & $7.5(1.1,13.9)$ & $7.3(2.0,12.6)$ & $7.5(1.9,13.2)$ \\
\hline Activity & $74(23)$ & $70(24)$ & $82(21)$ & $76(24)$ & $6.3(0.1,12.5)$ & $5.0(0.8,9.3)$ & $6.8(0.8,12.8)$ \\
\hline Recreation & $83(22)$ & $75(23)$ & $86(19)$ & $79(22)$ & $6.5(0.9,12.0)$ & $3.8(-0.9,8.5)$ & $3.1(-2.4,8.6)$ \\
\hline Shoulder & $82(26)$ & $73(33)$ & $87(25)$ & $81(28)$ & $5.3(-2.1,12.6)$ & $2.8(-2.4,8.0)$ & $4.7(-0.8,10.1)$ \\
\hline Mood & $77(23)$ & $74(27)$ & $83(22)$ & $77(24)$ & $6.1(-0.2,12.4)$ & $5.2(1.7,8.6)$ & $4.2(-0.7,9.1)$ \\
\hline Anxiety & $74(26)$ & $77(26)$ & $78(23)$ & $74(28)$ & $4.5(-2.4,11.4)$ & $6.1(0.0,12.1)$ & $6.9(-0.2,14.0)$ \\
\hline $\begin{array}{l}\text { UWQOL Physical } \\
\text { function subscale } \\
\text { score }\end{array}$ & $71(17)$ & $69(20)$ & $81(15)$ & $76(20)$ & $5.7(0.7,10.6)$ & $4.4(1.5,7.3)$ & $4.5(0.6,8.4)$ \\
\hline \multicolumn{8}{|c|}{ UWQOL physical function subscale domain scores } \\
\hline Appearance & $80(17)$ & $73(20)$ & $89(14)$ & $83(19)$ & $5.2(0.6,9.7)$ & $3.2(-0.3,6.6)$ & $2.2(-1.4,5.8)$ \\
\hline Swallowing & $78(22)$ & $76(23)$ & $86(16)$ & $80(25)$ & $5.7(0.0,11.4)$ & $4.6(-0.1,9.2)$ & $5.6(-0.5,11.7)$ \\
\hline Chewing & $65(31)$ & $67(32)$ & $80(27)$ & $75(32)$ & $4.7(-3.3,12.8)$ & $5.7(-1.3,12.7)$ & $6.2(-3.5,15.9)$ \\
\hline Speech & $83(18)$ & $79(21)$ & $90(15)$ & $83(20)$ & $6.9(2.1,11.7)$ & $4.9(0.7,9.2)$ & $4.3(0.7,8.0)$ \\
\hline Taste & $64(32)$ & $61(35)$ & 77 (28) & $70(32)$ & $6.9(-1.3,15.1)$ & $6.8(0.6,12.9)$ & $6.7(-0.4,13.7)$ \\
\hline Saliva & $58(32)$ & $57(33)$ & $67(32)$ & $62(31)$ & $4.5(-4.1,13.1)$ & $3.9(-2.0,9.9)$ & $2.3(-5.2,9.8)$ \\
\hline
\end{tabular}

ICC Intra-class correlation for physical subscale score estimated as 0.0125 , with $95 \%$ confidence interval of $(0,0.0786)$

${ }^{a}$ Baseline value: Quintile categorisation for UWQOL Physical function; 3-level categorisation into best score, dysfunction, and in-between these extremes for the 12 UWQOL domains

behind which was discussed in detail in the baseline results paper [18]; individual patient randomisation was ruled out because of the likely sensitization of consultants to using the PCI, which could have led to certain strategies being carried over to when control group patients were being seen. A further strength of the trial was the relatively small proportion of refusals and withdrawals through patient choice, and the number missed for logistical reasons by trial staff was also small. Another strength was the electronic data capture which, apart from the paper-based baseline questionnaire, virtually eliminated missing data in the outpatient clinic setting.

From this study, in terms of the primary outcome of less than good overall QOL at 12 months, the best estimate after various adjustments, including baseline level, was an absolute benefit at 12 months of about 5\% from the PCI intervention and a risk ratio of 0.83 which suggests about one in six patients might benefit. Interpretation, however, is made difficult due to wide confidence intervals that include no benefit at all.

Perhaps where the PCI approach is helping most for patients is through the social-emotional aspect of cancer recovery [30]. Although the benefit from PCI intervention of 4.6 units in the social-emotional subscale score at 12 months after adjustment seems small, it is clinically meaningful [22]. It is of note also that results for all 12 UW-QOL domains favoured the PCI with a small benefit (Table 5), with improvements also seen for both groups over time which probably reflects adaption over the year. Fear of recurrence is frequently raised by patients on the PCI (Fig. 2) and is recognised as a major concern over many follow-up consultations [31]. It remains to be fully evaluated but the hypothesis is that the prompt allows the patient permission to talk about this aspect and seek reassurance or further information. The PCI approach might be very helpful for those HNC patients likely to take a more passive role in medical consultations, such as patients of lower socioeconomic strata [32].

Previous studies [22] have shown that the domain and subscale scores of the UW-QOL, notably the social-emotional subscale, correlate with overall QoL. It is possible that the simplicity of the binary primary overall QOL outcome in this trial diluted the benefit patients gained from this intervention. When analysing the change in overall QOL across all six-response options for overall QOL, the PCI group appeared to do slightly better (Table 6). Given the variation in numbers of patients by consultant and variation in types of patients seen and treated, it was reassuring to see that the analyses at consultant level (Table 7) provided some support, be it at a rather simplistic summary level, of the main 
Table 6 Change in overall QOL from baseline to 12 months

\begin{tabular}{|c|c|c|c|c|}
\hline $\begin{array}{l}\text { Category } \\
\text { Change }^{\mathrm{a}}\end{array}$ & Baseline & Final & $\begin{array}{l}\text { PCI } \\
(N=100)\end{array}$ & $\begin{array}{l}\text { Control } \\
(N=105)\end{array}$ \\
\hline+4 & $\mathrm{~V}$ poor & V good & 1 & - \\
\hline+1 & $\mathrm{~V}$ poor & Poor & 2 & - \\
\hline 0 & $\mathrm{~V}$ poor & $\mathrm{V}$ poor & 1 & 2 \\
\hline+3 & Poor & V good & 2 & - \\
\hline+2 & Poor & Good & - & 1 \\
\hline+1 & Poor & Fair & 2 & 2 \\
\hline 0 & Poor & Poor & 1 & 1 \\
\hline+3 & Fair & Outstanding & 1 & - \\
\hline+2 & Fair & V good & 3 & 2 \\
\hline+1 & Fair & Good & 9 & 10 \\
\hline 0 & Fair & Fair & 8 & 8 \\
\hline-1 & Fair & Poor & - & 1 \\
\hline-2 & Fair & $\mathrm{V}$ poor & - & 1 \\
\hline+1 & Good & $V$ good & 20 & 14 \\
\hline 0 & Good & Good & 10 & 13 \\
\hline-1 & Good & Fair & 4 & 5 \\
\hline-2 & Good & Poor & - & 1 \\
\hline+1 & V good & Outstanding & 2 & 2 \\
\hline 0 & V good & V good & 19 & 23 \\
\hline-1 & V good & Good & 4 & 9 \\
\hline-2 & $V$ good & Fair & 3 & 2 \\
\hline-3 & $V$ good & Poor & - & 2 \\
\hline 0 & Outstanding & Outstanding & 1 & 2 \\
\hline-1 & Outstanding & V good & 4 & 2 \\
\hline-2 & Outstanding & Good & 2 & 1 \\
\hline-3 & Outstanding & Fair & - & 1 \\
\hline-4 & Outstanding & Poor & 1 & - \\
\hline
\end{tabular}

${ }^{\mathrm{a}}$ The UWQOL Overall QOL question has 6 category responses: Outstanding, Very good, Good, Fair, Poor, Very poor

findings reported at patient level. Whereas the unadjusted results for the DT (Table 3) tended to favour the PCI, as did the results after adjustment for baseline value and clustering, the results after full adjustment did not favour either group. No trial of this size stands alone as evidence and further trials would provide reassurance of the positive indications suggested by this trial.

The inclusion of the PCI does not significantly lengthen the consultation time since in comparison to the control group the first trial PCI consultations only took one minute longer on average whilst at 12 months they were one minute shorter.

One limitation of the trial was that it was under-powered, in part from a greater loss of patients than expected after identifying likely patients at the MDT and before the baseline trial clinic; half of this loss comprised patients who could not possibly have started the trial, for example, because of death, recurrence, palliation, changes in travel to non-trial sites and for other reasons, such as being in another trial and having mental health issues [18]. Further losses between baseline and the final trial clinic (Fig. 1) were predominantly for clinical reasons or because of COVID-19. Pragmatically, we accept that "size and power are irrelevant once the experiment has actually been carried out. At this point, the trial is analysed using confidence intervals to show the plausible values for the treatment effects" [33]. One unavoidable limitation was the lack of blinding but this is a distinctive feature of pragmatic cluster trials. Since recruitment of patients took place after the randomisation of clusters, there was always a possibility of selection bias, but this was minimised because patients were allocated to individual consultants through the cancer tracking referral process without knowing which consultants used PCI and which did not.

The focus of the project is now related to wider implementation of the PCI approach in clinical care, research around the mechanisms of action, ways of improving efficacy, and education resources for patients and clinicians. An implementation phase could include aspects of patient-clinician communication and patient empowerment. It would be interesting to apply the intervention earlier in the follow-up of patients as perhaps there might be more benefit, possibly starting in the pre-treatment phase. To achieve this, appropriate IT infrastructure is required to allow patients to access the PCI tool prior to their consultation and allow this to be integrated into clinical care. This needs to be part of an integrated strategy of engaging patients using IT technology. The need for IT solutions around COVID-19 might hasten the breakdown of barriers previously encountered by both patients and clinicians in respect of IT.

\section{Conclusion}

In summary, study is the first randomised controlled trial to evaluate the benefit of the PCI approach. Notable strengths of this study were the originality (landmark trial) with 15 consultants in a routine NHS outpatient setting, its clinical significance as a low-cost intervention and a strong contribution made by patients themselves to the design and delivery of the trial. Clinicians find the PCI straightforward to use, with minimal training, with the vast majority of patients appreciating the approach and wishing to continue to use it in the future. The study suggests a small but meaningful benefit in outcomes from this PCI approach using routine care. Such interventions are increasingly important given the rising incidence of $\mathrm{HNC}$, more people living longer with the burden of treatment-related issues and the importance of addressing unmet needs in the early post-treatment survivorship phase. 


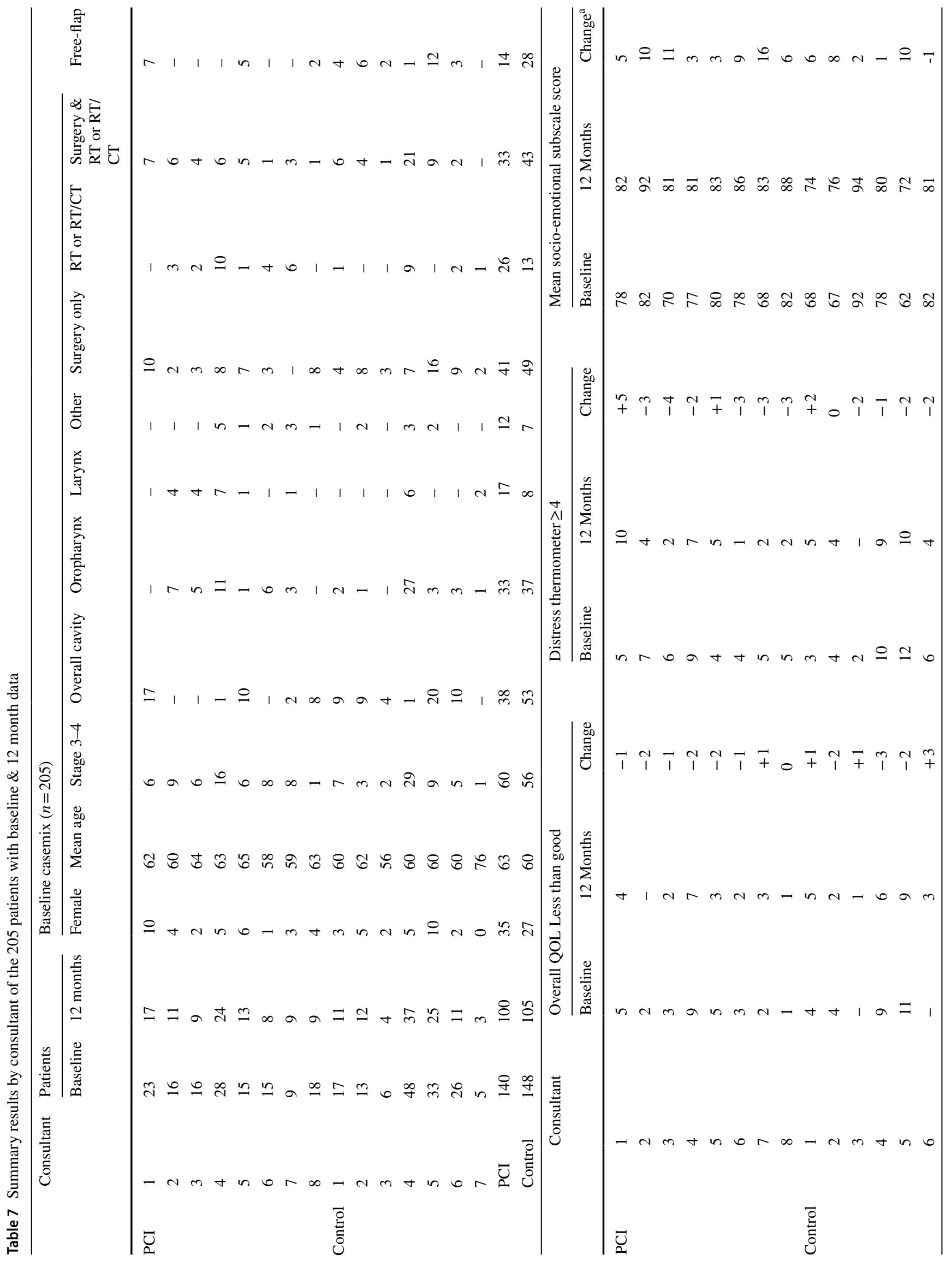


Acknowledgements This paper presents independent research funded by the National Institute for Health Research (NIHR) under its Research for Patient Benefit (RfPB) Programme (Grant Reference Number PB-PG-0215-36047). The views expressed are those of the author(s) and not necessarily those of the NIHR or the Department of Health and Social Care. In addition, this research was supported by the National Institute for Health Research (NIHR) infrastructure at Leeds (DenTCRUI).

Funding This trial is funded by the RfPB on behalf of the NIHR (PBPG-0215-36047). This paper presents independent research funded by the National Institute for Health Research (NIHR) under its Research for Patient Benefit (RfPB) Programme (Grant Reference Number PB-PG-0215-36047). The views expressed are those of the authors and not necessarily those of the NHS, the NIHR or the Department of Health. This trial is funded by the RfPB on behalf of the NIHR (PB-PG-0215-36047).

\section{Compliance with ethical standards}

Conflict of interest The authors declare that they have no known competing financial interests or personal relationships that could have appeared to influence the work reported in this paper. We do not have financial disclosure or any conflict of interest.

Ethical approval The PCI trial has ethical approval from North WestLiverpool Central Research Ethics Committee REC reference: IRAS 16/NW/0465, Project ID: 189554. It also has approval from the Health Research Authority (HRA). The Research and Development Department at Aintree University Hospital NHS Trust (AUH) is coordinating the trial and AUH is the sponsor for the trial. Trial registration: 32,382 . Clinical Trials Identifier, NCT03086629. The study complied with all aspects of ethical standards of clinical research.

Informed consent As part of the trial patients consented to the study.

Open Access This article is licensed under a Creative Commons Attribution 4.0 International License, which permits use, sharing, adaptation, distribution and reproduction in any medium or format, as long as you give appropriate credit to the original author(s) and the source, provide a link to the Creative Commons licence, and indicate if changes were made. The images or other third party material in this article are included in the article's Creative Commons licence, unless indicated otherwise in a credit line to the material. If material is not included in the article's Creative Commons licence and your intended use is not permitted by statutory regulation or exceeds the permitted use, you will need to obtain permission directly from the copyright holder. To view a copy of this licence, visit http://creativecommons.org/licenses/by/4.0/.

\section{References}

1. http://www.handle-on-qol.com

2. Rogers SN, Semple C, Babb M, Humphris G (2016) Quality of life considerations in head and neck cancer: United Kingdom national multidisciplinary guidelines. J Laryngol Otol 130(S2):S49-S52

3. Lee EW, Twinn S, Moore AP, Jones MP, Leung SF (2008) Clinical encounter experiences of patients with nasopharyngeal carcinoma. Integr Cancer Ther 7(1):24-32

4. Henry M, Alias A, Cherba M, Woronko C, Rosberger Z, Hier M, Zeitouni A, Kost K, Mlynarek A, Richardson K, Black M, MacDonald C, Chartier G, Frenkiel S (2020) Immediate post-treatment 
supportive care needs of patients newly diagnosed with head and neck cancer [published online ahead of print, 2020 Mar 18]. Support Care Cancer. https://doi.org/10.1007/s00520-020-05368-2

5. Ghazali N, Roe B, Lowe D, Rogers SN (2015) Patients concerns inventory highlights perceived needs and concerns in head and neck cancer survivors and its impact on health-related quality of life. Br J Oral Maxillofac Surg 53(4):371-379

6. Rogers SN, El-Sheikha J, Lowe D (2009) The development of a Patients Concerns Inventory (PCI) to help reveal patients concerns in the head and neck clinic. Oral Oncol 45(7):555-561

7. Miller N, Rogers SN (2018) A review of question prompt lists used in the oncology setting with comparison to the patient concerns inventory. Eur J Cancer Care (Engl). https://doi.org/10.1111/ ecc. 12489

8. Shunmugasundaram C, Rutherford C, Butow PN, Sundaresan P, Dhillon HM (2019) Content comparison of unmet needs selfreport measures used in patients with head and neck cancer: a systematic review. Psychooncology 28:2295-2306

9. Rogers SN, Thomson F, Lowe D (2018) The patient concerns inventory integrated as part of routine head and neck cancer follow-up consultations: frequency, case-mix, and items initiated by the patient. Ann R Coll Surg Engl 100:209-215

10. Rogers SN, Ahiaku S, Lowe D (2018) Is routine holistic assessment with a prompt list feasible during consultations after treatment for oral cancer? Br J Oral Maxillofac Surg 56(1):24-28

11. Rogers SN, Lowe D (2014) An evaluation of the head and neck cancer patient concerns inventory across the merseyside and cheshire network. Br J Oral Maxillofac Surg 52(7):615-623

12. Rogers SN, Gwane S, Lowe D, Humphris G, Yueh B, Weymuller EA (2002) The addition of mood and anxiety domains to the University of Washington quality of life scale. Head Neck 24(6):521-529

13. Laraway DC, Rogers SN (2012) A structured review of journal articles reporting outcomes using the University of Washington quality of life scale. Br J Oral Maxillofac Surg 50(2):122-131

14. Ghazali N, Kanatas A, Bekiroglu F, Scott B, Lowe D, Rogers SN (2013) The patient concerns inventory: a tool to uncover unmet needs in a cancer outpatient clinic. Bulletin of The Royal College of Surgeons of England 95(3):1-6

15. Rogers SN, Lowe D, Kanatas A (2016) Suitability of the patient concerns inventory as a holistic screening tool in routine head and neck cancer follow-up clinics. Br J Oral Maxillofac Surg $54: 415-421$

16. Rogers SN, Lowe D (2009) Screening for dysfunction to promote multidisciplinary intervention by using the University of Washington quality of life questionnaire. Arch Otolaryngol Head Neck Surg 135:369-375

17. Rogers SN, Lowe D, Lowies C, Yeo ST, Allmark C, Mcavery D, Humphris GM, Flavel R, Semple C, Thomas SJ, Kanatas A (2018) Improving quality of life through the routine use of the patient concerns inventory for head and neck cancer patients: a cluster preference randomized controlled trial. BMC Cancer 18:444

18. Rogers SN, Allmark C, Bekiroglu F, Tudor Edwards R, Fabbroni G, Flavel R, Highet V, Ho MWS, Humphris GM, Jones TM, Khattak O, Lancaster J, Loh C, Lowe D, Lowies C, Macareavy D, Moor J, Ong TK, Prasai A, Roland N, Semple C, Spencer LH, Tandon S, Thomas SJ, Schache A, Shaw RJ, Kanatas A (2020) Improving quality of life through the routine use of the patient concerns inventory for head and neck cancer patients: baseline results in a cluster preference randomised control [published online ahead of print, 2020 June 1]. Eur Arch Otorhinolaryngol. https://doi.org/10.1007/s00405-020-06077-6

19. Verhaeghe N, Clays E, Vereecken C, De Maeseneer J, Maes L, Van Heeringen C, De Bacquer D, Annemans L (2013) Health promotion in individuals with mental disorders: a cluster preference randomized controlled trial. BMC Public Health 13:657
20. Hegel MT, Collins ED, Kearing S, Gillock KL, Moore CP, Ahles TA (2008) Sensitivity and specificity of the distress thermometer for depression in newly diagnosed breast cancer patients. Psychooncology 17:556-560

21. https://euroqol.org/ [accessed August 2020].

22. Rogers SN, Lowe D, Yueh B, Weymuller EA (2010) The physical function and social-emotional function subscales of the University of Washington quality of life questionnaire (UW-QOL). Arch Otolaryngol Head Neck Surg 136(4):352-357

23. Semple C, Parahoo K, Norman A, McCaughan E, Humphris G, Mills M (2013) Psychosocial interventions for patients with head and neck cancer. Cochrane Database Syst Rev. https://doi. org/10.1002/14651858

24. Calver L, Tickle A, Moghaddam N, Biswas S (2018) The effect of psychological interventions on quality of life in patients with head and neck cancer: systematic review and meta-analysis. Eur J Cancer Care. https://doi.org/10.1111/ecc.12789

25. Richardson AE, Broadbent E, Morton RP (2019) A systematic review of psychological interventions for patients with head and neck cancer. Support Care Cancer 27(6):2007-2021

26. Turner J, Yates P, Kenny L, Gordon LG, Burmeister B, Hughes BGM, McCarthy AL, Perry C, Chan RJ, Paviour A, Skerman H, Batstone M, Mackenzie L (2019) The ENHANCES study: a randomised controlled trial of a nurse-led survivorship intervention for patients treated for head and neck cancer. Support Care Cancer 27(12):4627-4637

27. Van der Hout A, van Uden-Kraan CF, Holtmaat K, Jansen F, Lissenberg-Witte BI, Nieuwenhuijzen GAP, Hardillo JA, Baatenburg de Jong RJ, Tiren-Verbeet NL, Sommeijer DW, de Heer K, Schaar CG, Sedee RE, Bosscha K, van den Brekel MWM, Petersen JF, Westerman M, Honings J, Takes RP, Houtenbos I, van den Broek WT, de Bree R, Jansen P, Eerenstein SEJ, Leemans CR, Zijlstra JM, Cuijpers P, van de Poll-Franse LV, Verdonck-de Leeuw IM (2020) Role of eHealth application Oncokompas in supporting self-management of symptoms and health-related quality of life in cancer survivors: a randomised, controlled trial. Lancet Oncol 21(1):80-94

28. Basch E, Deal AM, Kris MG, Scher HI, Hudis CA, Sabbatini P, Rogak L, Bennett AV, Dueck AC, Atkinson TM, Chou JF, Dulko D, Sit L, Barz A, Novotny P, Fruscione M, Sloan JA, Schrag D (2016) Symptom monitoring with patient-reported outcomes during routine cancer treatment: a randomized controlled trial. J Clin Oncol 34(6):557-65. Doi: https://doi.org/10.1200/ JCO.2015.63.0830. Epub 2015 Dec 7. Erratum in: J Clin Oncol 2016 Jun 20;34 (18):2198. Erratum in: J Clin Oncol 2019 Feb 20;37(6):528. PMID: 26644527; PMCID: PMC4872028.

29. van der Meulen IC, May AM, de Leeuw JR, Koole R, Oosterom M, Hordijk GJ, Ros WJ (2014) Long-term effect of a nurse-led psychosocial intervention on health-related quality of life in patients with head and neck cancer: a randomised controlled trial. Br J Cancer 110(3):593-601. https://doi.org/10.1038/bjc.2013.733

30. Zhou Y, Humphris G, Ghazali N, Friderichs S, Grosset D, Rogers SN (2015) How head and neck consultants manage patients' emotional distress during cancer follow-up consultations: a multilevel study. Eur Arch Otorhinolaryngol 272(9):2473-2481

31. Ghazali N, Cadwallader E, Lowe D, Humphris G, Ozakinci G, Rogers SN (2013) Fear of recurrence among head and neck cancer survivors: longitudinal trends. Psychooncology 22(4):807-813

32. Allen S, Rogers SN, Harris RV (2019) Socio-economic differences in patient participation behaviours in doctor-patient interactionsA systematic mapping review of the literature. Health Expect 22(5):1173-1184

33. Spiegelhalter D (2019) The Art of Statistics: Learning from Data Pelican books. ISBN 978-0-241-39863-0 P 287.

Publisher's Note Springer Nature remains neutral with regard to jurisdictional claims in published maps and institutional affiliations. 


\section{Affiliations}

\section{Simon N. Rogers ${ }^{1,2}$ (1) $\cdot$ Christine Allmark $^{3} \cdot$ Fazilet Bekiroglu $^{2} \cdot$ Rhiannon Tudor Edwards $^{4} \cdot$ Gillon Fabbroni $^{3}$. Robert Flavel $^{5}$. Victoria Highet ${ }^{6}$. Michael W. S. Ho ${ }^{3}$. Gerald M. Humphris ${ }^{7}$. Terry M. Jones ${ }^{8} \cdot$ Owais Khattak $^{2}$. Jeffrey Lancaster ${ }^{2} \cdot{\text { Christopher } \text { Loh }^{2} \cdot \text { Derek Lowe }^{9} \cdot \text { Cher Lowies }^{6} \cdot \text { Dominic Macareavy }^{10} \cdot \text { James Moor }^{3} \cdot \text { T. K. Ong }}^{3}$. A. Prasai ${ }^{3} \cdot$ Nicholas Roland $^{2}$. Cherith Semple ${ }^{11,12(1)} \cdot$ Llinos Haf Spencer ${ }^{4} \cdot$ Sank Tandon $^{2} \cdot$ Steven J. Thomas ${ }^{13}$. Andrew Schache ${ }^{2} \cdot$ Richard J. Shaw $^{2} \cdot$ Anastasios Kanatas $^{3}$}

Christine Allmark

allmarkc@yahoo.co.uk

Fazilet Bekiroglu

fbekiroglu@doctors.org.uk

Rhiannon Tudor Edwards

r.t.edwards@bangor.ac.uk

Gillon Fabbroni

gillon.fabbroni@nhs.net

Robert Flavel

robertflavel@btinternet.com

Victoria Highet

victoria.highet@liverpoolft.nhs.uk

Michael W. S. Ho

michael.ho2@nhs.net

Gerald M. Humphris

gmh4@st-andrews.ac.uk

Terry M. Jones

t.m.jones@liverpool.ac.uk

Owais Khattak

owais.khattak@aintree.nhs.uk

Jeffrey Lancaster

jeffrey.lancaster@aintree.nhs.uk

Christopher Loh

christopher.loh@liverpoolft.nhs.uk

Derek Lowe

astraglobeltd@btconnect.com

Cher Lowies

cher.lowies@gmail.com

Dominic Macareavy

dominic.macareavy@btinternet.com

James Moor

jamesmoor@nhs.net

T. K. Ong

tk.ong@nhs.net

A. Prasai

aprasai@nhs.net

Nicholas Roland

nick.roland@liverpoolft.nhs.uk

Cherith Semple

cherith.Semple@setrust.hscni.net

Llinos Haf Spencer

spencer@bangor.ac.uk
Sank Tandon

sankalap.tandon@liverpoolft.nhs.uk

Steven J. Thomas

steve.thomas@bristol.ac.uk

Andrew Schache

andrew.schache@liverpool.ac.uk

Richard J. Shaw

richard.shaw@liverpool.ac.uk

Anastasios Kanatas

anastasios.kanatas@nhs.net

1 Faculty of Health and Social Care, Edge Hill University, Ormskirk, Liverpool L39 4QP, UK

2 Liverpool Head and Neck Centre, Liverpool University Hospital Aintree, Liverpool, UK

3 Leeds Teaching Hospitals and St James Institute of Oncology, Leeds Dental Institute and Leeds General Infirmary, Leeds, UK

4 Centre for Health Economics and Medicines Evaluation (CHEME), School of Health Sciences, College of Human Sciences, Ardudwy Hall, Normal Site, Bangor University, Bangor, Wales, UK

5 Southway, Guilford, Surrey, UK

6 Liverpool Head and Neck Clinical Trials, Clinical Sciences Building, University Hospital Aintree, Liverpool, UK

7 School of Medicine, Medical \& Biological Sciences, North Haugh, St Andrews, UK

8 Liverpool Head and Neck Centre, University of Liverpool, Cancer Research Centre, University of Liverpool, 200 London Road, Liverpool L3 9GA, UK

9 Astraglobe Ltd, Congleton, Cheshire, UK

10 Chair of the Head and Neck Patient and Carer Research Forum, Liverpool Head and Neck Centre, Liverpool University Hospital Aintree, Liverpool, UK

11 Institute of Nursing and Health Research, Ulster University, Shore Road, Belfast, Newtownabbey, Co BT37 0QB, Antrim, Belfast, UK

12 South Eastern Health and Social Care Upper Newtownards Road, Belfast BT16 1RH, UK

13 Oral and Maxillofacial Surgery Department, Bristol University, Lower Maudlin Street, Bristol, UK 